\title{
When gentlemen are first and ladies are last: Effects of gender stereotypes on the order of romantic partners' names
}

\author{
Peter Hegarty*, NilaWatson, Laura Fletcher and Grant McQueen \\ University of Surrey, Guildford, UK
}

British Journal of Social Psychology (2011), 50, 21-35.

\begin{abstract}
A preference to name stereotypically masculine before stereotypically feminine individuals explains why men are typically named before women, as on the Internet, for example (Study 1). Heterosexual couples are named with men's names first more often when such couples are imagined to conform to gender stereotypes (Studies 2 and 3 ). First named partners of imaginary same-sex couples are attributed more stereotypically masculine attributes (Study 4). Familiarity bounds these effects of stereotypes on name order. People name couples they know well with closer people first (Study 5), and consequently name familiar heterosexual couples with members of their own gender first (Study 6). These studies evidence a previously unknown effect of the semantics of gender stereotypes on sentence structure in the everyday use of English.
\end{abstract}

William Shakespeare never wrote plays titled 'Juliet and Romeo', 'Cressida and Troilus', or 'Cleopatra and Anthony'. Had he done so, he would have flouted the prescriptions of grammarians of his time who advised that 'in speaking at the leaste, let us kepe a natural order, and set the man before the woman for manners sake' (Wilson, 1553, cited in Bodine, 1975). In the sixteenth and seventeenth centuries, English grammarians argued for the correctness, naturalness, and propriety of naming men before women on the grounds that men were the worthier and the more comprehensive sex (Bodine, 1975). Few psychologists are familiar with this history of proscribing a male-first order in binomial phrases (Malkiel, 1959) such as 'king and queen', 'his and hers', 'Mr and Mrs', or the names of romantic couples in the titles of Shakespeare's plays. To our knowledge, Brown (1986, p. 484) is the only psychologist who has ever described the prescription to name men before women as a case of sexist language.

We think that Brown (1986) was right, and his recognition went unacknowledged. Specifically, we propose that while the original sexist prescriptions to name men before women may be largely forgotten, gender stereotypes continue to affect how people order the names of romantic partners. Indeed, far from being a phenomenon of the past, such [page 22] effects are evident in very modern contexts, such as Internet websites and the naming of lesbian and gay couples. Our hypothesis that gender stereotypes affect the ordering of names draws together social psychological research on gender stereotypes, cognitive, and linguistic studies of word order, and recent findings that gender stereotypes affect the ordering of visual representations of women and men in pictures (Maass, Suitner, Favaretto, \& Cignacchi, 2009) and graphs (Hegarty, Lemieux, \& McQueen, in press).

\section{Gender stereotypes}

Gender stereotypes are belief structures that describe physical attributes, interests, occupations, and sexual orientations as if they all made up a single dimension; masculinity-femininity (Deaux \& Lewis, 1984). At their most basic level of meaning, these stereotypes both proscribe, and appear to explain, women's and men's assortment into unequal 'homemaker' and 'breadwinner' roles in the past, the present, and in imagined alternate realities (Diekman \& Eagly, 2000; Eagly, 1987; Hoffman \& Hurst, 1990). While social psychologists' knowledge of the effects of gender stereotypes is too vast to be summarized here (but see Kite, Deaux, \& Haines, 2008), three aspects of those stereotypes are particularly relevant to our hypotheses.

First, at their most basic, gender stereotypes assume that femininity is made up of communal traits and masculinity of agentic traits (e.g. Deaux \& Lewis, 1984; Eagly, 1987). These contents of gender stereotypes may be relevant to word order effects because both memory experiments (McDonald, Bock, \& Kelly, 1993) and analysis of linguistic corpora (Benor \& Levy, 2006) show that speakers of English prefer to construct binomial phrases with agentic entities before passive entities (e.g. 'people and things' or 'living and dead', see also Cooper \& Ross, 1975). Consequently, we predicted that people stereotyped as masculine would be named before people stereotyped as feminine. Second, 
our hypothesis emphasizes stereotypic masculinity-femininity rather than gender categories per se; stereotypic feminine and masculine behaviours, roles, traits, and preferences activate stereotypic associations more than gender categories do (Deaux \& Lewis, 1984; Pratto \& Bargh, 1991). For example, gay men and lesbians are stereotyped as 'feminine' and 'masculine', respectively, by virtue of their respective orientations towards male and female partners, even though gay men are men and lesbians are women (Kite \& Deaux, 1987, see also Butler, 1990; Hegarty \& Pratto, 2001). Consequently, our hypothesis makes predictions as to how both same-sex and opposite-sex couples are named. Third, like all stereotypes, gender stereotypes are most likely to be active when little individuating information is known about the target (Deaux \& Major, 1987; Fiske \& Neuberg, 1990). Consequently, we predict that effects of gender stereotypes on name order will occur when wholly unfamiliar couples are named, but not when familiar couples are named.

It may seem odd to predict that gender stereotypes could affect something as seemingly abstract and asocial as word order. However, our hypothesis is further motivated by recent research on the effects of gender stereotypes on the visual ordering of information in pictures and graphs. Speakers of languages read from left-to-right, such as English, draw and interpret visual images from left-to-right (Chatterjee, Southwood, \& Basilico, 1999; Maass \& Russo, 2003). Such people also position men to the left of women in pictures to the extent that they stereotype men as more agentic than women (Maass et al., 2009). Similarly, data representing men is spontaneously graphed first, ahead of data representing women, and powerful groups are graphed ahead of weaker groups (Hegarty \& Buechel, 2006: Hegarty et al., in press). Indeed, Maass et al. (2009) [page 23] theorized that preferences for ordering the genders in images are causally related to the tendency to position agents before subjects in human languages. In this context, our hypothesis that gender stereotypes affect word order appears considerably less surprising.

\section{Linguistic explanations of name order preferences}

We are not the first social scientists to attempt to explain a preference to name men before women. Linguists have highlighted two plausible reasons why men's names might habitually go before women's: name phonology and name popularity. In English, men's names typically contain fewer syllables than women's names, are less likely to begin or end in vowels, and are more likely to begin and end in obstruent, hardersounding consonants (Barry \& Harper, 1995; Cassidy, Kelly, \& Sharoni, 1999; Cutler, McQueen, \& Robinson, 1990; Lieberson \& Bell, 1992; Slater \& Feinman, 1985). These statistical differences may reflect different linguistic roots of female and male names in English (Hough, 2000), and the differences are sufficiently robust that connectionist models, human children, and human adults can all consistently predict the gender of real and nonsense names (Cassidy et al., 1999; Lieberson \& Mikelson, 1995; Whissell, 2001). Phonological differences between female and male English names have been hypothesized to be both a cause (Wright, Hay, \& Bent, 2005) and a consequence (Cutler et al., 1990) of the preference to address men before women.

Female and male names in English also vary in popularity. The most popular male names are given to more children than are the most popular female names (Lieberson \& Bell, 1992), and more girls than boys are assigned original unique names (Lieberson \& Mikelson, 1995). These differences emerge, in part, because girls are more often named on the basis of name aesthetics, and boys are more often named for an older family member (Rossi, 1965). Consequently, male names remain popular across decades more consistently than do female names (Lieberson, Dumais, \& Bauman, 2000). These differences in name popularity might explain name order preferences; binomial phrases tend to position common words before uncommon words, both when word order has become fixed (Fenk-Oczlon, 1989), and when word order remains variable (Benor \& Levy, 2006).

The most sustained linguistic analysis of the preference to name men before women was offered by Wright et al. (2005). These authors argued that a 'phonological conspiracy' leads men to be named before women, and found evidence that men's names tend to go before women's on the Internet (see alsoWright \& Hay, 2002).Wright et al. (2005) were informed by Cooper and Ross' (1975) claims about the phonological characteristics of 'linguistic freezes'; those binomials in which the order of elements has become fixed and idiomatic (e.g. 'salt and pepper', 'gin and tonic', and 'spic and span'). Wright et al. (2005) asked students to express a preference for alternate forms of sentences that varied name order within a binomial phrase. When the two names had similar phonology but different gender, students - particularly male students - preferred to position male names first. For example, sentences 
containing the binomial phrase 'John and Jen' were preferred to sentences containing the binomial phrase 'Jen and John'. However, when names were matched for gender, participants preferred sentences which positioned more common names first, names with fewer syllables first, and names that began and ended with obstruent consonants first. These phonological preferences for name order overlapped considerably with the phonological preferences for word order in linguistic freezes described by Cooper and Ross (1975). [page 24]

\section{The present research}

To what extent does our stereotyping hypothesis overlap with Wright et al.'s (2005) phonological conspiracy hypothesis? The four experiments and two observational studies presented below point to similarities and differences. First, like Wright and Hay (2002), we predicted that men's names would be positioned before women's on the Internet (Study 1). However, we have drawn different implications from Cooper and Ross' (1975) statement on binomial phrases than Wright et al. (2005) did. Cooper and Ross (1975) emphasized that semantic rules would outweigh phonological rules in determining word order preferences, and the phonological rules they proposed have received only mixed support in memory experiments (McDonald et al., 1993; Pinker \& Birdsong, 1979), and analyses of linguistic corpora (Benor \& Levy, 2006; Fenk- Oczlon, 1989). Our stereotyping hypothesis similarly predicts that semantics outweigh phonology and that men are named first to the extent that couples are perceived through the lens of gender stereotypes. In two experiments, we manipulated the extent to which heterosexual couples were understood to conform to gender stereotypes to test this claim (Studies 2 and 3).

Moreover, the gender stereotyping and phonological conspiracy hypothesis differ in that the former emphasizes stereotypical masculinity-femininity, while the latter emphasizes sex differences in the characteristics of names. As a result, the gender stereotyping hypothesis makes unique predictions as to how same-sex couples will be named, and these predictions are tested in Study 4. Finally, only the gender stereotyping hypothesis predicts that familiarity with the couple being named will moderate name order preferences. Cooper and Ross (1975) laid particular stress upon a semantic 'me first' rule; 'here and there' is preferred to 'there and here', for example. Name order may be affected by such a rule where a person feels closer to one member of a couple than the other. In our last two studies, we tested whether people name well-known heterosexual couples with closer individuals first, in a naturalistic setting (Study 5) and in an experiment (Study 6).

\section{STUDY 1: NAME ORDER ON THE INTERNET}

\section{Method}

The first study aimed simply to test whether there is a preponderance of pairings of female and male names on the Internet with the male name positioned first. Wright and Hay (2002) counted the number of 'hits' produced by 18 name pairs by an Internet search in 1998 and found that combinations with male names first produced more hits. We replicated their study with two larger sets of names here. The British set included the 10 most popular names given to boys and the 10 most popular names given to girls in 2004 in England and Wales (see Office of National Statistics, n.d. a, b, for actual names). The second American set of names used the 10 most popular female and male names from the 1990 United States Census (see United States Census Bureau, n.d., for actual names). No name occurred on both lists. For each search, we recorded the number of 'hits' estimated by searches for webpages that contained conjunctions of each of the 100 possible female-male name pairs in a female-first binomial phrase (e.g. 'Emily and Jack') and a male-first binomial phrase (e.g. 'Jack and Emily'), using the search engine www.google.com on 8 November 2005. [page 26]

\section{Results and discussion}

British searches produced, on average, 1,677 hits with male-first binomials but only 467 hits with female-first binomials. American searches yielded 13,428 hits on average with male-first binomials, but only 5,846 hits with female-first binomials. For three of the British name pair combinations, equal numbers of hits were produced by searches with female-first and male-first binomials. Otherwise, male-first binomials produced the greater number of hits among the British searches $(N=68), x^{2}(1)=$ 
15.68, $p<.001$, and American searches $(N=77), \mathrm{x}^{2}(1)=29.16, p<.001$. In other words, we replicated Wright and Hay's (2002) findings.

\section{STUDY 2: TRADITIONAL AND NON-TRADITIONAL COUPLES}

While the first study showed that male names are often positioned first, it did not inform the question of why names are ordered in thismanner. Study 2 was a simple experimental test of our hypothesis that gender stereotypes affect name order. We hypothesized that male names would be positioned first more often when heterosexual couples were imagined to conform to gender stereotypes than when they were imagined to deviate from them.

\section{Method}

\section{Participants}

Eighty-six women and thirty-five men participated at public campus venues $(N=79)$ or in class $(N=$ 48 ) as volunteers ( $M$ age $=25.0$, range $=18-60$ years). Like all subsequent experiments, Study 3 was conducted at one of two English universities.

\section{Materials and procedure}

In two conditions, participants read instructions to think of an imaginary heterosexual couple who 'are quite [traditional/non-traditional], and who [conform strictly to/deviate radically from] gender scripts about how the two genders should behave'. In both conditions, participantswere next asked a series of items which served as a manipulation check. They indicated which partner earned more money, which did more housework, which was more interested in art, which was more interested in science and technology, which was more interested in sport, and which was more interested in fashion. Responses that indicated the female partner for the second, third, and sixth questions, and responses which indicated the male partner for the first, fourth, and fifth questions indicated that the couple were imagined to conform to gender stereotypes. Next, participants were instructed to write down five name combinations for their imaginary couple. This measure comprised the principle dependent variable. Participants completed the materials in class or at public campus venues and were subsequently debriefed.

\section{Results and discussion}

To check that the manipulation had been effective, we calculated the proportion of stereotype conforming responses generated by each participant. Non-traditional couples [page 26] were stereotyped less than traditional couples ( $M s=0.44,0.95$, respectively), $t(74)=10.36, p<.001 .{ }^{1} \mathrm{We}$ proceeded by analysing the principle dependent variable next. Men positioned men's names first more than chance predictions, $(M=0.73), t(34)=3.82, p=.001$, but women did not, $(M=0.53), t<1$. Traditional couples were named with men's names first more often than chance predictions, $(M=$ $0.69), t(60)=3.67, p=.001$, but non-traditional couples were not $(M=0.49), t<1$. A $2 \times 2$ ANOVA showed effects of both participant gender, $F(1,114)=4.69, p<.05, \eta_{p}^{2}=.039$, and condition, $F(1,114)$ $=5.55, p<.05, \eta_{p}^{2}=.046$ on the proportion of male names positioned first. These two main effects did not interact, $F<1$. These results support our hypothesis that gender stereotypes affect name order, suggesting that semantic beliefs rather than phonological characteristics affect name order. Furthermore, as in Wright et al.'s (2005) study, men preferred male-first orders more than women did. We return to this gender difference below.

\section{STUDY 3: NAME ORDER AND HISTORICAL TIME}

Study 3 was a conceptual replication of Study 2. Diekman and Eagly (2000) observed that women and men are imagined to have inhabited more traditional gender roles in the past than in the present. Building on their work, we used historical time to operationalize imaginary couples' conformity or deviation from traditional gender roles. We predicted that couples imagined to live in earlier periods of history would be named with men first more often than couples imagined to live more recently. 


\section{Method}

\section{Participants}

Eighty women and eighty men participated in a university library $(N=96)$ or on-line $(N=64)$ as volunteers $(M$ age $=22.5$ years, range $=18-66$ years $)$.

\section{Materials and procedure}

The study was presented as an investigation of 'people's awareness of popular names from different time periods'. In four conditions, participants were asked to imagine 'writing a story about a couple living in [the 1920s/1950s/1980s/the 21st century]' and to list 'ten couples' names that you think may suit the couple you are imagining'. The paper version of the survey was distributed in a university library. An invitation to complete the on-line version was distributed to undergraduate students. An email contact for debriefing was provided in both contexts. The Internet site was closed once the design had been filled.

\section{Results and discussion}

Overall, participants positioned male names first more often than chance predictions $(M=0.66)$, onesample $t(159)=5.20, p<.001$. A $2 \times 4$ ANOVA investigated effects of [page 27] decade and participant gender on the proportion of male names positioned first. A main effect of gender was observed, $F(1,159)=14.36, p<.001, \eta_{p}^{2}=.086$. As in Study 2, men positioned men's names first more often than chance would predict $(M=0.73), t(79)=6.60, p<.001$, butwomen did not $(M=0.55)$, $t(79)=1.20, p>20$. The effect of decade was not significant, $F<1.1$, but the interaction between decade and participant gender was significant, $F(3,152)=5.85, p=.001, \eta_{p}^{2}=.104$. Tukey's post hoc test revealed that women in the 1980s and twenty-first century conditions positioned men's names first less than women in the other conditions, and less than men in all four conditions (see Table 1).

Table I. Proportion of couples named with male name first by participant gender and imagined decade (Study 3)

\begin{tabular}{lllll}
\hline Decade & $1920 \mathrm{~s}$ & $1950 \mathrm{~s}$ & $1980 \mathrm{~s}$ & Twenty-first century \\
\hline Participant gender & & & & \\
Female & $.69^{*}$ & $.68^{*}$ & .39 & .42 \\
Male & .63 & $.70^{* *}$ & $.76^{* * * *}$ & $.84^{* * * *}$ \\
\hline
\end{tabular}

${ }^{*} p<.05 ; * * p<.01 ; * * * p<.001$. Significance tests are two-tailed $t$ tests testing deviation from a theoretical mean of .50 within each cell.

In Study 3, the manipulation of historical time affected women's, but not men's, name order preferences. As in Study 2, men were more likely to name couples with men first overall. We examined gender differences in the naming of imaginary couples again in our final study, but first we present the strongest test of our hypotheses that it is stereotypically masculine people, rather than men, who are named first when imaginary couples are called to mind.

\section{STUDY 4: SAME-SEX COUPLES}

Heretofore, we have presented evidence that men are named before women when opposite-sexed couples are named because gender stereotypes affect name order preferences. In Study 4, we asked people to imagine same-sex couples. Gender stereotypes lead people to expect lesbian and gay people to have 'gender inverted' attributes (Kite \& Deaux, 1987), but Study 4 required participants to attribute a series of stereotypically feminine and masculine attributes more to one partner of a same-sex couple than to the other. We predicted that first-named partners would be attributed 
stereotypically masculine attributes, and that second named partnerswould be attributed stereotypically feminine attributes.

\section{Method}

\section{Participants}

Forty-seven women and thirty-nine men participated in class $(N=42)$ or at public campus venues $(N=44)$ as volunteers ( $M$ age $=22.9$, range $=18-57$ years).

\section{Materials and procedure}

Participants read instructions to think about either an imaginary lesbian or gay couple and to write names for their couple using the following stem: [page 28]

My imaginary couple are called and

Six items then allowed participants to describe differences between the partners in their imaginary couple. The items pertained to differences in annual earnings, household labour, interest in sports, interest in fashion, physical smallness, and physical strength. Items required the participants to write the partners' names into comparative statements, endowing each attribute to one partner more than to the other. For example, the final two items pertaining to physical attributes were presented as follows:

is physically smaller than

is physically stronger than

The six items were written such that a participant who positioned one partner's name first consistently across items would endow that partner with an equal number of stereotypically feminine and masculine attributes. The performance of household labour, interest in fashion, and physical smallness were categorized as stereotypically feminine attributes. High earnings, interest in sports and physical strength were categorized as stereotypically masculine attributes. Participants completed the materials in class or at public campus venues and were subsequently debriefed.

\section{Results and discussion}

Responses that stereotyped first-named partners as 'feminine' were coded as 0 and those that stereotyped first-named partners as 'masculine' were coded as 1 . All six items were averaged to form a reliable measure of the stereotypical masculinity of the first-named partner,,$=.76$. Consistent with predictions, first-named partners were imagined to possess fewer feminine attributes and more masculine attributes than chance would predict $(M=0.38,0.62$, respectively), $t(85)=3.52, p=.001$. A $2 \times 2 \times 2$ ANOVA with couple gender (women vs. men), participant gender (women vs. men), and data collection site (classroom vs. public venue) showed no significant main effects or interactions that qualified this attribution of masculine attributes to the first-named partner, all $F<1$. For each of the six stereotyping items, the stereotypically masculine attribute was attributed to the first-named partnermore than $50 \%$ of the time, significantly more so in all cases except the earnings item, all other $p<.01$.

These results support our hypothesis that name order is associated with beliefs about individuals' stereotypically feminine and masculine traits rather than their status as women or men per se. In sum, the last three studies suggest that modern English speakers do not follow a 'male-first' rule when they name couples. Rather, they align name order with the stereotypical masculinity-femininity of the two partners in a couple.

\section{STUDY 5: CHRISTMAS CARDS}

The gender stereotyping and phonological conspiracy theory not only differ in their predictions about the naming of same-sex couples, they also make different predictions as to how familiarity moderates 
preferences for naming couples. Study 5 tests our hypothesis that when the individuals named are highly familiar that effects of stereotypes on name order are absent (Fiske \& Neuberg, 1990). To conduct Study 5, we 'shuttled back', in Lewinian fashion, from the laboratory to the real world, to observe how peoplenamed couples that they knew well. In contrast to the anonymous medium of the Internet, Study 5 examined how couples are addressed in Christmas cards exchanged [page 29] between friends and family. In this context - and in contrast to both the Internet and earlier experiments, interpersonal closeness may play a role in name order preferences. Hence, we predicted that name order preferences would follow a 'me-first' rule (Cooper \& Ross, 1975) rather than gender stereotypes, and that people would address closer people first in Christmas cards.

\section{Method}

\section{Informants and procedure}

Seventeen people who were married to, or co-habiting with, an opposite-sex partner acted as volunteer informants (age range $=36-79$ for female partners, and 38-85 for male partners, Ms = $53.82,54.82$, respectively). Informants were not 'research participants' in the sense traditional to psychological research. Informants helped us to interpret the naming behaviour of their friends and family, but we did not study their naming behaviour at all. Specifically, prior to the $2007(N=13)$ or $2008(N=4)$ Christmas season, each informant agreed to retain every Christmas card they received. Each informant subsequently sorted the cards into piles that were sent by a person or family that knew the informant best, knew their partner best, or who know both partners equally well. We then investigated name order in the cards that were sent by someone who was closer to one of the two partners, and we debriefed the informants about the study's purpose.

\section{Results and discussion}

Each informant supplied 7-53 cards, and a total of 492 cards were sent by individuals or families who were closer to either an informant or to their partner. More cards were sent by people who were closer to female partners than male partners $\left(N=327\right.$ vs. 165 , respectively), $X^{2}(1)=53.34, p<.001$. As predicted, most cards named the better-known partner rather than the less well-known partner first. This pattern emerged whether the better-known partner was the female partner $(N=301,26), x^{2}(1)=$ $231.27, p<.001$, or the male partner, $(N=132,35), 22(1)=56.34, p<.001$. No preference to name men first was observed. Rather, a 'me-first' rule (Cooper \& Ross, 1975) described $88 \%$ of the cards that informants received. These results confirm our predictions that well-known couples are named in ways that are affected by interpersonal closeness and not by gender stereotypes.

\section{STUDY 6: NAMING FRIENDS, FAMILY, AND IMAGINARY COUPLES}

The Study 5 informants received many cards from other couples and families, but the identity of the person who actually wrote each card was difficult to discern. As a result, we were unable to tell whether women and men differed in the ways that they addressed the informants and their partners. In our final study, we aimed to further examine how name order preferences are moderated by familiaritywith the couple being named, and to examine whether preferences to name closer people firstwould lead to gender difference in the naming of familiar couples. Women and men form more close friendships with members of the same sex than with members of the opposite sex (Caldwell \& Peplau, 1982). Consequently, ame-first rule should lead people to name same-sex individuals first when naming familiar heterosexual couples. In Study 6, women and men named familiar [page 30] couples and imaginary couples to test both the hypothesis that naming preferences were moderated by familiarity, and the hypothesis that familiar couples are named with same-sex people first.

\section{Method}

\section{Participants}

Thirty-nine women and thirty-eight men participated at public campus venues as volunteers $(M$ age $=26.7$, range $=17-50$ years $)$. 


\section{Materials and procedure}

Materials asked participants to write the names of four couples in their family, four couples among their friends, and the names of four imaginary couples. Participants were approached on campus, invited to participate, and subsequently debriefed.

\section{Results and discussion}

Table 2 shows the proportion of couples of each type that women and men named by listing men's names first. A $3 \times 2$ ANOVA with couple type (family vs. friends vs. imaginary) as a within-subject factor, participant gender (female vs. male) as a between subjects factor, and the proportion of couples with men's names first as the dependent variable revealed several effects. Men named a greater proportion of couples with men's names first than women did ( $M s=0.69,0.40$, respectively), $F(1,75)=33.61, p<.001, \eta_{p}^{2}=.309$. These proportions also varied by task, $F(1,75)=10.18, p<.001$, $\eta_{p}{ }^{2}=.119$, and the effects of task and gender interacted, $F(1,75)=4.17, p<.05, \eta_{p}^{2}=.052$. Tukey's post hoc test (alpha $=.05$ ) revealed that women named men first more often when naming imaginary couples than when naming friends or family members. Men named men first with equal frequency across all three tasks.

Table 2. Proportion of couples named with male name first by participant gender and couple type (Study 5)

\begin{tabular}{lccc}
\hline Couple type & Family & Friends & Imaginary \\
\hline $\begin{array}{l}\text { Participant gender } \\
\text { Female }\end{array}$ & $.34^{* * * *}$ & $.32^{* * * *}$ & .55 \\
Male & $.62^{*}$ & $.73^{* * * *}$ & $.74^{* * * *}$ \\
\hline *p $<.05 ; *$ **kp $<.001$. Significance tests are two-tailed $t$ tests testing deviation from a theoretical \\
mean of .50.
\end{tabular}

As in Studies 2 and 3, imaginary heterosexual couples were named with men's names first, particularly by men. However, when participants named familiar couples first, same-sex people were named first, consistent with a 'me-first' preference. This latter effect may partially explain why gender differences in the naming of imaginary people were observed in this study, and in earlier studies (i.e. Wright et al., 2005; Studies 2 and 3). When asked to imagine couples, women and men may draw on the names of familiar couples as one way of completing such tasks. Responding in this manner would lead women to name women first and men to name men first when naming opposite-sexed [page 31] couples. Consistent with this explanation, positive correlations were observed in Study 6 between the proportion of male names positioned first when naming friends and kin, $r(77)=.49, p<.001$, friends and imaginary couples, $r(77)=.50, p<.001$, and kin andimaginary couples, $r(77)=.38, p=.001{ }^{2}$

\section{GENERAL DISCUSSION}

Many centuries ago, English language speakers were proscribed to name men before women so that everybody's language use would reflect a patriarchal order which was said to be natural and proper. Contemporary speakers of English may not know the history of English grammar, but their implicit thoughts about gender groups and personal relationships continue to inform the way that they order names, both in experimental studies (Studies 2, 3, 4, and 6) and 'real-world' contexts (Studies 1 and 5). Jointly these six studies lead to the conclusion that people habitually name men first in oppositesex couples because male partners are believed to be more stereotypically masculine kinds of people than female partners (Studies 2 and 3).While somewhat counter-intuitive, this conclusion appears the most parsimonious explanation of the attribution of masculine attributes to the first-named partner in same-sex couples (Study 4). As in other domains, the effects of stereotypes on name order disappear 
when individuating information is rich (Study 5). When naming familiar people, women, and men position members of their own gender first most often (Study 6).

Our analysis of name order preferences differs from earlier linguistic explanations of such preferences (Cutler et al., 1990; Wright et al., 2005). Hypotheses based on static linguistic differences between women's andmen's names are unable to explain the kinds of situational variation in name order preferences shown here. As such, name order preferences exemplify a more general property of stereotyping; static group differences provide essentialist explanations (cf. Medin, 1989) that only appear to explain why groups behave differently or ought to be treated differently (Hegarty \& Pratto, 2001; Hoffman \& Hurst, 1990; Yzerbyt, Rocher, \& Schadron, 1997). Female and male names differ statistically in popularity and phonology just as female and male bodies differ statistically in size, shape, longevity, and other attributes. However, such differences - whether linguistic or bodily cannot account for the manner in which stereotyping is moderated by familiarity with the possible targets of stereotypes (cf. Deaux \& Major,1987; Fiske \& Neuberg, 1990). Study 4 demonstrates most clearly that name order is associated with properties attributed to women and men, rather than properties inherent in women and men's names. The fact that romantic partners usually have different genders from each other is neither a necessary (Study 4), nor a sufficient (Study 2), condition for the effects of gender stereotypes on name order to be observed.

While our conclusions differ from Wright et al.'s (2005), some of these differences may be explained by differences in our methodologies. Speakers of British English, studied here, and of American English, in Wright et al.'s (2005) studies, may name couples differently. Also, our participants called to mind names, while Wright et al.'s (2005) participants chose between two sentences with different name orders. In their experiments, participants may have been more likely to rehearse how each name order sounds before alighting on a preferred name order. Phonological properties may affect [page 32] choices of name orders to a greater extent in such choice tasks. Additionally, our experiments asked people to name couples, butWright et al. (2005) did not describe the relationship between the women and men in their sentences. We are currently testing the degree to which couple status bounds the effects observed here in studies in which people imagine women and men who are friends or romantic partners. Finally, while we reached different conclusions from Wright et al. (2005), we would like to point out that we would not have reached those conclusions without the benefit of their original thought-provoking work.

In one regard, our results agree strongly with those of Wright et al. (2005); any 'conspiracy' to name men first is largely a conspiracy of men. Male participants in Studies 2, 3, and 6 named imaginary couples with male names first $73-75 \%$ of the time, while female participants in these students wrote male names first only $53-55 \%$ of the time. ${ }^{3}$ Moreover, women were affected by our subtle historical cue about traditional gender roles while men were not (Study 3 ). It seems unlikely that these gender difference result from men holding stronger gender stereotypes than women; such gender differences are rarely observed (Kite et al., 2008), and women and men stereotyped same-sex couples similarly here (Study 4). Instead, women and men may draw on knowledge of well-known couples when naming imaginary couples, just as knowledge of familiar names is generalized to unfamiliar names in other contexts (Nuttin, 1987). Such a process might explain the interaction of gender and historical time in Study 3; participants may have drawn on the names of couples that they know well to a greater extent when imagining couples in the present than in the distant past. Alternatively women and men may have understood the relationship between historical time and gender stereotypes differently. Diekman and Eagly (2000) found that participants of both genders stereotyped more modern women as more agentic than traditional women, while stereotypes of men differed less by historical period. In Study 3, women may have stereotyped modern women as more agentic than women in the past to a greater extent than male participants did.

These studies bear a family resemblance to other research demonstrating subtle effects of gender stereotypes on the ordering of information in pictures (Maass et al., 2009) and graphs (Hegarty et al., in press). However, we would caution against the interpretation that effects of gender stereotypes on order are manifestations of identical processes in verbal and visual domains. To be sure, people prefer to position more agentic entities first in pictures (Maass et al., 2009) and in binomial phrases (McDonald et al., 1993). Furthermore, Maass et al. (2009) argue that the subject-object order of human languages is partially responsible for the bias to position more agentic groups first in the leftright axis. However, in contrast to the results of the experiments above, Hegarty et al. (in press) showed that powerful groups are positioned first in graphs, but masculine groups are not. While first- 
named partners in same-sex couples were attributed more masculine attributes in Study 4, we have found that English-language speakers attribute feminine and masculine attributes equally to members of same-sex couples positioned on the left of images presented to them and images that they draw themselves (Hegarty, 2009). Finally, the gender differences observed here and in other [page 33] studies of naming (Wright et al., 2005) are not consistently reported in studies of the ordering of imagery representing women and men in pictures and graphs (Hegarty et al., in press; Maass et al., 2009, but see also Suitner \& Maass, 2007).

A comparison of the effects of gender stereotypes on visual and verbal order also suggests the possibility of a reciprocal relationship between such stereotypes and name order. People not only are quicker to identify the names of high power groups when they appear in the upper part of the visual field (Schubert, 2005), but they also attribute more power to an individual the further that individual is positioned vertically above others within a diagram (Giessner \& Schubert, 2007). Hegarty et al. (in press) showed a second way that ordering can contribute to stereotypes; people who attribute 'bias' to a graph's author on the basis of the order of information in that graph assume that the author is biased in favour of the group graphed first. Accordingly, name order may do more than reflect the effects of gender stereotyped thoughts on language structure. Name order may communicate gender stereotypes either directly by affecting listeners' beliefs, or indirectly by affecting listeners' beliefs about speakers' beliefs.

\section{Conclusions}

Many centuries ago, English speakers were enjoined to name men before women on the basis of explicitly sexist beliefs about women and men (Bodine, 1975). In a modern culture where such beliefs are seen as antiquated and wrong, the sexism that persists in likely to be subtle and unacknowledged in form (Swim, Aikin, Hall, \& Hunter, 1995). Indeed, behavioural preferences to make women the 'second sex' in both pictures and words appear to have outlived the largely forgotten patriarchal prescriptions for such conventions (see Curzan, 2003; Hall, 2008, respectively). In this context, Brown's (1986) overlooked recognition thatword order might be a form of sexist language is all the more striking, and all the more relevant for contemporary understandings of sexist language.

\section{Footnotes.}

1. The degrees of freedom reported for this $t$ test is less than $n-1$ because a Levene's test for equality of variance showed the sample variance to be far greater in the non-traditional couple condition than in the traditional couple condition ( $\mathrm{SD}=0.38,0.11$, respectively), $\mathrm{F}(123)=$ 105.27, $\mathrm{p}<.001$.

2. These correlations were not mediated by participant gender, all $|Z|<1$.

3. Indeed, women may not contribute to the naming conspiracy at all. In Studies 2, 3, and 6, each of the 205 women named imaginary couples with men first, on average, in $54.1 \%$ of their responses. While consistently higher than .50 across the three studies, this proportion was not significantly higher than chance in any study, or even when the women's data were collapsed across studies, $\mathrm{t}(204)=1.54, \mathrm{p}<.12$.

\section{Acknowledgements}

We thank Martyn Barrett, Felicia Pratto, Michelle Ryan, and Annette Sterr for their comments on earlier versions of this manuscript.

\section{References}

Barry, H. B., \& Harper, A. S. (1995). Increased choice of female phonetic attributes in first names. Sex Roles, 32, 809-819. doi:10.1007/BF01560190

Benor, S. B., \& Levy, R. (2006). The chicken or the egg? A probabilistic analysis of English binomials. Language, 82, 233-278.

Bodine, A. (1975). Androcentrism in prescriptive grammar. Language in Society, 4, 129-146. 
Brown, R. (1986). Social psychology: The second edition. New York: Macmillan Free Press.

Butler, J. (1990). Gender trouble: Feminism and the subversion of identity. New York: Routledge.

Caldwell, M. A., \& Peplau, L. A. (1982). Sex differences in same-sex friendship. Sex Roles, 8, 721-732. doi:10.1007/BF00287568

Cassidy, K.W., Kelly,M.H.,\&Sharoni, L. J. (1999). Inferring gender from name phonology. Journal of Experimental Psychology: General, 128, 362-381. doi:10.1037/0096-3445.128.3.362

Chatterjee, A., Southwood, M. H., \& Basilico, D. (1999). Verbs, events, and spatial representations. Neuropsychologia, 37, 395-402. doi:10.1016/S0028-3932(98)00108-0

Cooper, W., \& Ross, J. (1975). World order. Chicago Linguistic Society, 11, 63-111. [page 34]

Curzan, A. (2003). Gender shifts in the history of English. Cambridge, UK: Cambridge University Press.

Cutler, A., McQueen, J., \& Robinson, K. (1990). Elizabeth and John: Sound patterns of men's and women's names. Journal of Linguistics, 26, 471-482.

Deaux, K., \& Lewis, L. L. (1984). Structure of gender stereotypes: Interrelationship among components and gender labels. Journal of Personality and Social Psychology, 46, 991-1004

Deaux, K., \& Major, B. (1987). Putting gender into context: An interactive model of gender-related behaviour. Psychological Review, 94, 369-389. doi:10.1037/0022-3514.46.5.991

Diekman, A. B., \& Eagly, A. H. (2000). Stereotypes as dynamic constructs: Women and men of the past, present, and future. Personality and Social Psychology Bulletin, 26, 1171-1188. doi:10.1177/0146167200262001

Eagly, A. H. (1987). Sex differences in social behavior: A social-role interpretation. Hillsdale, NJ: Erlbaum.

Fenk-Oczlon, G. (1989). Word frequency and word order in freezes. Linguistics, 27, 517-556.

Fiske, S. T., \& Neuberg, S. L. (1990). A continuum of impression formation from categorybased to individuating processes: Influences of information and motivation on attention and interpretation. In M. P. Zanna (Ed.), Advances in experimental social psychology (pp. 1-74). San Diego, CA: Academic Press.

Giessner, S. R., \& Schubert, T. W. (2007). High in the hierarchy: How vertical location and judgments of leaders power are related. Organizational Behavior and Human Decision Processes, 104, 30-44. doi:10.1016/j.obhdp.2006.10.001

Hall, J. (2008). The sinister side: A lost key to Western art. New York: Oxford University Press.

Hegarty, P. (2009). The spatial attribution bias and implicit inversion stereotypes. Unpublished data: University of Surrey.

Hegarty, P., \& Buechel, C. (2006). Androcentric reporting of gender differences in APA journals: 1965-2004. Review of General Psychology, 10, 377-389. doi:10.1037/1089-2680.10.4.377

Hegarty, P., Lemieux, A. F., \& McQueen, G. (in press). Graphing the order of the sexes: Constructing, recalling, interpreting and putting the self in gender difference graphs. Journal of Personality and Social Psychology.

Hegarty, P., \& Pratto, F. (2001). The effects of social category norms and stereotypes on explanations for intergroup differences. Journal of Personality and Social Psychology, 80, 723-735. doi:10.1037/0022-3514.80.5.723

Hoffman, C., \& Hurst, N. (1990). Gender stereotypes: Perception or rationalization? Journal of Personality and Social Psychology, 58, 197-208. doi:10.1037/0022-3514.58.2.197

Hough, C. (2000). Towards an explanation of phonetic differentiation in masculine and feminine personal names. Journal of Linguistics, 36, 1-11.

Kite, M. E., \& Deaux, K. (1987). Gender belief systems: Homosexuality and the inversion theory. Psychology of Women Quarterly, 11, 83-96. doi:10.1111/j.1471-6402.1987.tb00776.x

Kite, M. E., Deaux, K., \& Haines, E. L. (2008). Gender stereotypes. In F. L. Denmark \& M. A. Paludi (Eds.), Psychology of women: A handbook of issues and theories (2nd ed., pp. 205-236). Westport, CT: Praeger.

Lieberson, S. L., \& Bell, E. O. (1992). Children's first names: An empirical study of social taste. American Journal of Sociology, 98, 511-554. doi:10.1086/230048

Lieberson, S. L., Dumais, S., \& Bauman, S. (2000). The instability of androgynous names. American Journal of Sociology, 105, 1249-1287.

Lieberson, S. L., \& Mikelson, K. (1995). Distinctive African-American names: An experimental, historical, and linguistic analysis of innovation. American Sociological Review, 60, 928-946.

Maass, A., \& Russo, A. (2003). Directional bias in the mental representation of spatial events: Nature or culture? Psychological Science, 14, 296-301. doi:10.1111/1467-9280.14421

Maass, A., Suitner, C., Favaretto, X., \& Cignacchi, M. (2009). Groups in space: Stereotypes and the spatial agency bias. Journal of Experimental Social Psychology, 45, 496-504. doi:10.1016/j. 
jesp.2009.01.004

Malkiel, Y. (1959). Studies in irreversible binomials. Lingua, 8, 113-160. [page 35]

McDonald, J. L., Bock, K., \& Kelly, M. H. (1993). Word and world order: Semantic, phonological, and metrical determinants of serial position. Cognitive Psychology, 25, 188-230. doi:10.1006/ cogp.1993.1005

Medin, D. L. (1989). Concepts and conceptual structure. American Psychologist, 44, 1469-1481. doi:10.1037/0003-066X.44.12.1469

Nuttin, F. M. (1987). Affective consequences of mere ownership: The name letter effect in twelve European languages. European Journal of Social Psychology, 17, 381-402. doi:10.1002/ejsp. 2420170402

Office of National Statistics (n.d. a). Top 100 names for baby boys in England and Wales. Retrieved November 1, 2005, from http://www.statistics.gov.uk/specials/babiesnames boys. asp

Office of National Statistics (n.d. b). Top 100 names for baby girls in England and Wales.

Retrieved November 1, 2005, from http://www.statistics.gov.uk/specials/babiesnames girls. asp

Pinker, S., \& Birdsong, D. (1979). Speakers' sensitivity to rules of frozen word order. Journal of Verbal Learning and Verbal Behavior, 18, 497-508. doi:10.1016/S0022-5371(79)90273-1

Pratto, F., \& Bargh, J. A. (1991). Stereotyping based on apparently individuating information: Trait and global components of sex stereotypes under attention overload. Journal of Experimental Social Psychology, 27, 26-74. doi:10.1016/0022-1031(91)90009-U

Rossi, A. S. (1965). Naming children in middle-class families. American Sociological Review, 30, 499-513.

Schubert, T.W. (2005). Your highness: Vertical positions as perceptual symbols of power. Journal of Personality and Social Psychology, 89, 1-21. doi:10.1037/0022-3514.89.1.1

Slater, A. S., \& Feinman, S. (1985). Gender and the phonology of North American first names. Sex Roles, 13, 429-440. doi:10.1007/BF00287953

Suitner, C., \& Maass, A. (2007). Positioning bias in portraits and self-portraits: Do female artists make different choices? Empirical Studies of the Arts, 25, 71-95. doi:10.2190/ X458-8V17-5M35-5549

Swim, J. K., Aikin, K. J., Hall, W. S., \& Hunter, B. A. (1995). Sexism and racism: Old-fashioned and modern prejudices. Journal of Personality and Social Psychology, 68, 199-214. doi:10.1037/ 0022-3514.68.2.199

United States Census Bureau (n.d.). Genealogy. Retrieved November 1, 2005, from http://www. census.gov/genealogy/names/names files.html

Whissell, C. (2001). Cues to referent gender in randomly constructed names. Perceptual and Motor Skills, 93, 856-858. doi:10.2466/PMS.93.7.856-858

Wright, S., \& Hay, J. (2002). Fred and Wilma: A phonological conspiracy. In S. Benor, M. Rose, D. Sharma, J. Sweetland \& Q. Zhang (Eds.), Gender and linguistic practice (pp. 175-191). Stanford, CA: CSLI Publications.

Wright, S., Hay, J.,\&Bent, T. (2005). Ladies first? Phonology, frequency, and the naming conspiracy. Linguistics, 43, 531-561.

Yzerbyt, V., Rocher, S., \& Schadron, G. (1997). Stereotypes as explanations: A subjective essentialistic view of group perception. In R. Spears, P. J. Oakes, N. Ellemers, \& S. A. Haslam (Eds.), The social psychology of stereotyping and group life (pp. 20-50). Oxford: Blackwell.

Received 25 August 2009; revised version received 3 December 2009 